\title{
1L NER1006 can improve rates of adequate and high-quality bowel cleansing in the right colon: a post hoc analysis of two randomised clinical trials
}

\author{
Jonathan Manning ${ }^{1}$, Juha Halonen ${ }^{2}$, Sandra Jose Cheriyamkunnel ${ }^{2}$ and Marco Antonio Álvarez-González ${ }^{3}$
}

\begin{abstract}
Background: The right colon is difficult to cleanse compared with other colon segments. This post hoc analysis of two randomised clinical trials (MORA and NOCT) examined whether $1 \mathrm{~L}$ polyethylene glycol (PEG) NER1006 and two mid-volume alternatives could improve adequate and high-quality cleansing in the right colon among patients with complete cleansing assessments.

Methods: Patients received NER1006 (N2D), 2L PEG plus ascorbate (2LPEG) or oral sulphate solution (OSS) as a 2-day evening/morning split-dosing regimen or NER1006 as a same-day morning-only dosing regimen (N1D). Patients had full segmental scoring assigned by treatment-blinded central readers using the Harefield Cleansing Scale. The right colon adequate (score $\geq 2$ ) and high-quality (score $\geq 3$ ) cleansing success of NER1006 (N2D and N1D) versus 2LPEG and OSS was analysed individually and as pooled groups (N2D vs. 2LPEG/OSS). We assessed the comparative right colon cleansing rates of the N2D versus $2 \mathrm{LPEG} / \mathrm{OSS}$ in overweight males. We also performed a multivariable regression analysis to examine factors affecting cleansing in the right colon.
\end{abstract}

Results: A total of 1307 patients were included. Pooled N2D showed significantly improved rates of adequate-level cleansing in the right colon compared with 2 LPEG (97.5\% [504/517] vs. 94.6\% [246/260]; $p=0.020)$ and OSS (97.5\% [504/517] vs. 93.8\% [244/260]; $p=0.006$ ). In MORA, the rate of adequate right colon cleansing did not significantly differ between N1D and 2LPEG (95.2\% [257/270] vs. 94.6\% [246/260]; $p=0.383)$. The rate of right colon high-quality cleansing was significantly improved with N2D or N1D vs. 2LPEG ( $p<0.001$ for both), and was numerically higher with N2D versus OSS ( $p=0.11)$. In overweight males, NER1006 delivered numerically higher adequate $(p=0.398)$ and superior high-quality $(p=0.024)$ cleansing rates versus $2 \mathrm{LPEG} / \mathrm{OSS}$. Multivariable regression analysis showed NER1006 was associated with adequate and high-quality cleansing ( $p=0.031$ and $p<0.001)$, while time between preparation and colonoscopy was negatively associated ( $p=0.034$ and $p=0.006$ ).

Conclusions: NER1006 delivered improved rates of adequate and high-quality right colon cleansing compared with 2LPEG and OSS. The increased rate of high-quality cleansing with NER1006 versus its comparators was also seen in overweight males.

\footnotetext{
*Correspondence: JHalonen@norgine.com

${ }^{2}$ Norgine Ltd, Medical Affairs, Widewater Place Moorhall Road, Harefield,

Uxbridge UB9 6NS, UK

Full list of author information is available at the end of the article
} original author(s) and the source, provide a link to the Creative Commons licence, and indicate if changes were made. The images or other third party material in this article are included in the article's Creative Commons licence, unless indicated otherwise in a credit line to the material. If material is not included in the article's Creative Commons licence and your intended use is not permitted by statutory regulation or exceeds the permitted use, you will need to obtain permission directly from the copyright holder. To view a copy of this licence, visit http://creativecommons.org/licenses/by/4.0/. The Creative Commons Public Domain Dedication waiver (http://creativeco mmons.org/publicdomain/zero/1.0/) applies to the data made available in this article, unless otherwise stated in a credit line to the data. 
Keywords: Bowel preparation, Bowel cleansing, Colonoscopy, Colorectal cancer, Low volume, Polyethylene glycol, Right colon

\section{Background}

Screening colonoscopy for colorectal cancer (CRC) reduces $\mathrm{CRC}$ incidence and mortality due to the detection and removal of premalignant lesions [1]. Adequate bowel preparation is an essential pre-procedural clinical requirement that determines the diagnostic yield and therapeutic benefits of colonoscopy [2]. According to the European Society of Gastrointestinal Endoscopy (ESGE), the minimum standard for the rate of adequate bowel preparation is $90 \%$, while the target standard is $\geq 95 \%$ [3]. However, in clinical practice these recommendations are usually unmet [4].

Generally, adequate cleansing is more difficult to attain in the right colon compared with other colon segments [5]. Moreover, the onco-protective effects of colonoscopy in the right colon are perceived to be relatively lower than those conferred by colonoscopy in the left colon $[1,6]$. It has been hypothesised that inadequate cleansing can lead to missed lesions in the right colon, which is frequently found to have predominantly flat and non-pedunculated lesions [7-10]. Therefore, ensuring successful cleansing in the right colon is fundamental to maximising the protection against right-sided CRCs.

Clinical guidelines recommend both high- and low-volume polyethylene glycol (PEG)-based bowel preparations for routine bowel cleansing $[11,12]$. Low-volume PEGbased cleansing agents, such as the 1L PEG-based bowel preparation NER1006, have been shown to be as effective as high-volume agents, but reduce the requirement for high-volume preparation intake and thus improve overall patient adherence to treatments [13].

In randomised clinical trials, NER1006 has shown superior rates of right colon high-quality cleansing versus 2L PEG plus ascorbate (2LPEG; the MORA study), and numerically higher rates of right colon high-quality cleansing versus oral sulphate solution (OSS; the NOCT study) $[14,15]$. The improved cleansing efficacy of NER1006 in these trials is consistent with the results reported in a recent Italian prospective observational study, which enrolled 1289 patients to receive $4 \mathrm{~L}, 2 \mathrm{~L}$ or 1L PEG-based solutions for colon cleansing before undergoing colonoscopy [16]. The study reported superior cleansing in the right colon in patients who received NER1006 compared with other high-volume PEG-based bowel preparations.

Our aim in this post hoc analysis of data from the MORA and NOCT trials was to specifically examine whether NER1006 compared with 2LPEG and/or OSS can attain higher adequate-level and high-quality cleansing success rates in the right colon. Finally, we investigated the cleansing impact of NER1006 in the right colon in patients who are at increased risk of inadequate bowel preparation.

\section{Methods \\ Patients}

The MORA and NOCT trials included both male and female patients aged 18-85 years with varied demographic and clinical characteristics who required a screening, surveillance or diagnostic colonoscopy. This post hoc analysis mainly used data from the modified full analysis set 2 (mFAS2) of the two trials, which included all patients with full segmental Harefield Cleansing Scale (HCS) scorings by treatment-blinded central readers. The mFAS2 population only included patients who underwent colonoscopy with a colon-cleansing assessment, which better reflects a patient population undergoing colonoscopy by endoscopists in a real-world setting.

\section{Study design}

This is a post hoc analysis of two parallel, randomised, multicentre, central reader treatment-blinded, Phase III clinical trials (MORA and NOCT) that assessed the bowel-cleansing efficacy, safety and tolerability of NER1006 relative to two other active bowel preparation comparators, preceding colonoscopy, in adults. The study methods involved in each of the clinical trials and the results obtained have been detailed previously [14, 15]. In MORA, patients were randomly assigned (1:1:1) to receive NER1006, administered either as a 2-day evening/morning split-dosing regimen (N2D) or as a sameday morning-only dosing regimen (N1D), or 2LPEG as a 2-day evening/morning split-dosing regimen. In NOCT, patients were randomly assigned $(1: 1)$ to receive NER1006 or OSS, each provided as a 2-day evening/ morning split-dosing regimen. Product formulations are described in Additional file 1: Table S1. Both of the NER1006 regimens allowed a light breakfast and light lunch, and N1D allowed a light dinner. 2LPEG and OSS were administered as per their labels: 2LPEG permitted meals, including a light dinner (clear soup and/or plain yoghurt), while OSS allowed only breakfast on the day before colonoscopy. The first dose of each evening/morning split-dose regimen was started at 18:00 on the evening before the colonoscopy. After those dietary restrictions, patients could consume only clear fluids ad libitum until 
$2 \mathrm{~h}$ (NER1006 and OSS) or $1 \mathrm{~h}$ (2LPEG) before the start of the colonoscopy. Cleansing performance was initially evaluated by site endoscopists using the HCS, and then by central readers using video evaluation.

\section{Assessments}

The main objective of this post hoc analysis was to assess the attainment of adequate-level cleansing success and also high-quality cleansing in the right colon, as assessed by central readers using the HCS, in patients with complete cleansing data.

We compared right colon adequate-level cleansing success rates for N2D (combined) and N1D versus 2LPEG or OSS; right colon adequate-level cleansing success rates for the combined N2D regimens versus the combined populations treated with 2LPEG or OSS (2LPEG/OSS).

To expand our understanding of high-quality cleansing success, we also assessed the following outcomes per treatment: comparative right colon high-quality cleansing success rate for N2D (combined) and N1D versus 2LPEG or OSS; right colon high-quality cleansing success rates for the combined N2D versus the 2LPEG/OSS population. Lastly, we studied the cleansing efficacy of N2D versus 2LPEG/OSS in the right colon of males with body mass index $(\mathrm{BMI}) \geq 25 \mathrm{~kg} / \mathrm{m}^{2}$, as these patients are commonly known to be at increased risk for both inadequate cleansing and CRC [17]. The rates of right colon adequate and high-quality cleansing success with N2D versus 2LPEG/OSS were compared separately in overweight males and those without these risk factors for inadequate cleansing.

\section{Statistical analysis}

For each trial, patient information and central readerrecorded HCS scores were extracted from the data collected to calculate the proportion of patients who had adequate cleansing success in the right colon and the proportion who had high-quality cleansing success in the right colon. Success rates are presented as percentages. The one-sided t-test was used to assess the superiority of NER1006 versus its comparators for both adequate and high-quality cleansing success rates. Finally, the onesided $\mathrm{t}$-test was used to determine the $\mathrm{p}$-values for the combined analyses. Comparisons between overweight male patients and all other patients used two-sided t-tests, assuming equal variance. Right colon adequate and high-quality cleansing success rates with NER1006 versus comparators in overweight males and, separately, in all other patients, were compared using the one-sided t-test.

To assess the effect of variables that might influence the rates of adequate or high-quality right colon cleansing in the study population as a whole, we performed a multivariable logistical regression analysis with variables of: age, sex, BMI, study cohort, colonoscopy indication, time lapse between preparation completion and colonoscopy start, and NER1006 as the bowel preparation assigned. Two regression models were generated with adequate and high-quality right colon cleansing as the outcomes assessed.

A $p<0.05$ was considered significant.

\section{Results}

\section{Patient population}

Baseline characteristics of the mFAS2 population are summarised in Table 1. Baseline characteristics in mFAS2 were comparable across treatment arms, except for some imbalances observed in the sex and age distribution between the N2D and 2LPEG arms in MORA. Patient disposition is presented in Fig. 1. The mFAS2 population comprised 1307 patients, including 792 patients in MORA (N1D: 270; N2D: 262; 2LPEG: 260) and 515 patients in NOCT (N2D: 255; OSS: 260).

\section{Adequate-level cleansing success Comparative right colon adequate-level cleansing success} Among patients who had their bowel preparations administered as an evening/morning split-dose regimen, pooled N2D data showed significantly improved adequate-level cleansing in the right colon compared with 2LPEG (97.5\% [504/517] versus 94.6\% [246/260]; $p=0.020)$ and OSS (97.5\% [504/517] versus 93.8\% [244/260]; $p=0.006$; Fig. 2a). In the MORA study, rates of adequate right colon cleansing did not significantly differ between N1D and 2LPEG (95.2\% [257/270] versus $94.6 \%$ [246/260]; $p=0.383$ ).

\section{Combined analysis}

Significantly superior rates of adequate-level cleansing success were shown in combined data from the N2D regimens in MORA and NOCT versus combined 2LPEG/ OSS $(97.5 \%$ [504/517] vs $94.2 \%$ [490/520], $p=0.004)$ (Fig. 2b).

\section{High-quality cleansing success Comparative right colon high-quality cleansing success} Analysis of the evening/morning split-dose preparations showed that patients receiving an N2D regimen had a significantly higher rate of high-quality cleansing than patients receiving 2LPEG (36.0\% [186/517] versus $15.8 \%$ [41/260]; $p<0.001$ ), and a numerically higher rate than patients receiving OSS $(36.0 \%[186 / 517]$ versus $31.5 \%$ [82/260]; $p=0.11$ ). In MORA, rates of high-quality cleansing were significantly improved with N1D compared with 2LPEG (34.4\% [93/270] versus 15.8\% [41/260]; $p<0.001$ ) (Fig. 3a). 
Table 1 Patient characteristics of the mFAS2 population (MORA and NOCT combined)

\begin{tabular}{|c|c|c|c|c|}
\hline Characteristic & $\mathrm{N} 2 \mathrm{D}(\mathrm{n}=517)$ & $\mathrm{N} 1 \mathrm{D}(\mathrm{n}=\mathbf{2 7 0})$ & 2LPEG $(n=260)$ & OSS $(n=260)$ \\
\hline \multicolumn{5}{|l|}{ Sex, n (\%) } \\
\hline Female & $280(54.1)$ & $145(53.7)$ & $123(47.3)$ & $115(44.2)$ \\
\hline Male & $237(45.8)$ & $125(46.3)$ & $137(52.7)$ & $145(55.8)$ \\
\hline \multicolumn{5}{|l|}{ Age group, n (\%) } \\
\hline$\leq 65$ years & $400(77.4)$ & $210(77.8)$ & $214(82.3)$ & $213(81.9)$ \\
\hline$>65$ years & $117(22.6)$ & $60(22.2)$ & $46(17.7)$ & $47(18.1)$ \\
\hline \multicolumn{5}{|l|}{ Race, n (\%) } \\
\hline White/Caucasian & $473(91.5)$ & $267(98.9)$ & $257(98.8)$ & $215(82.7)$ \\
\hline Black & $36(7.0)$ & $3(1.1)$ & $1(0.4)$ & $24(9.2)$ \\
\hline Asian & $7(1.4)$ & 0 & $2(0.8)$ & $16(6.2)$ \\
\hline Other & $6(1.2)$ & 0 & 0 & $5(1.9)$ \\
\hline BMI, n & 514 & 268 & 256 & 260 \\
\hline Mean $\left(\mathrm{kg} / \mathrm{m}^{2}\right)(\mathrm{SD})$ & $28.4(5.3)$ & $26.9(4.3)$ & $26.4(4.1)$ & $29.7(6.2)$ \\
\hline Patients with $\mathrm{BMI}>25 \mathrm{~kg} / \mathrm{m}^{2}, \mathrm{n}(\%)$ & $371(72.2)$ & $175(65.3)$ & $154(60.2)$ & $201(77.3)$ \\
\hline \multicolumn{5}{|l|}{ Colonoscopy indication, n (\%) } \\
\hline Screening & $283(54.7)$ & $137(50.7)$ & $129(49.6)$ & $157(60.4)$ \\
\hline Surveillance & $141(27.3)$ & $57(21.1)$ & $60(23.1)$ & $76(29.2)$ \\
\hline Diagnosis & $93(18.0)$ & $76(28.1)$ & $71(27.3)$ & $27(10.4)$ \\
\hline Time lapse-preparation to colonoscopy, n & 512 & 266 & 253 & 258 \\
\hline $\begin{array}{l}\text { Mean (SD) time (hours) between the last dose of } \\
\text { bowel preparation and colonoscopy }\end{array}$ & $5.6(1.9)$ & $5.4(1.7)$ & $5.4(2.1)$ & $5.3(2.1)$ \\
\hline
\end{tabular}

2LPEG, 2 L polyethylene glycol plus ascorbate; BMI, body mass index; mFAS2, modified full analysis set 2; N1D, NER1006 same-day morning-only dosing regimen; N2D, NER1006 2-day evening/morning split-dosing regimen; OSS, oral sulphate solution; SD, standard deviation
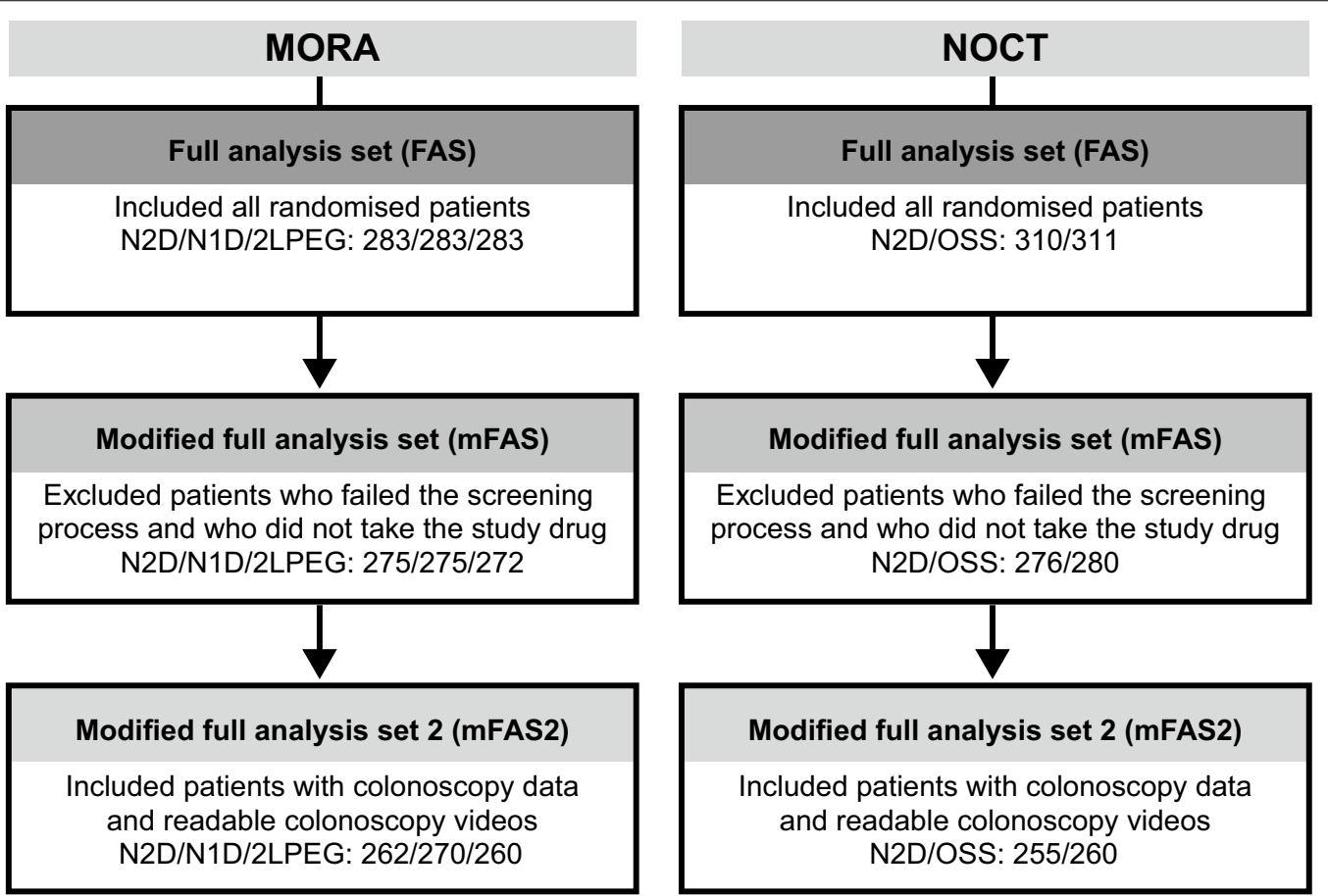

Fig. 1 Patient disposition. 2LPEG, 2L polyethylene glycol plus ascorbate; N1D, NER1006 same-day morning-only dosing regimen; N2D, NER1006 2-day evening/morning split-dosing regimen; OSS, oral sulphate solution 


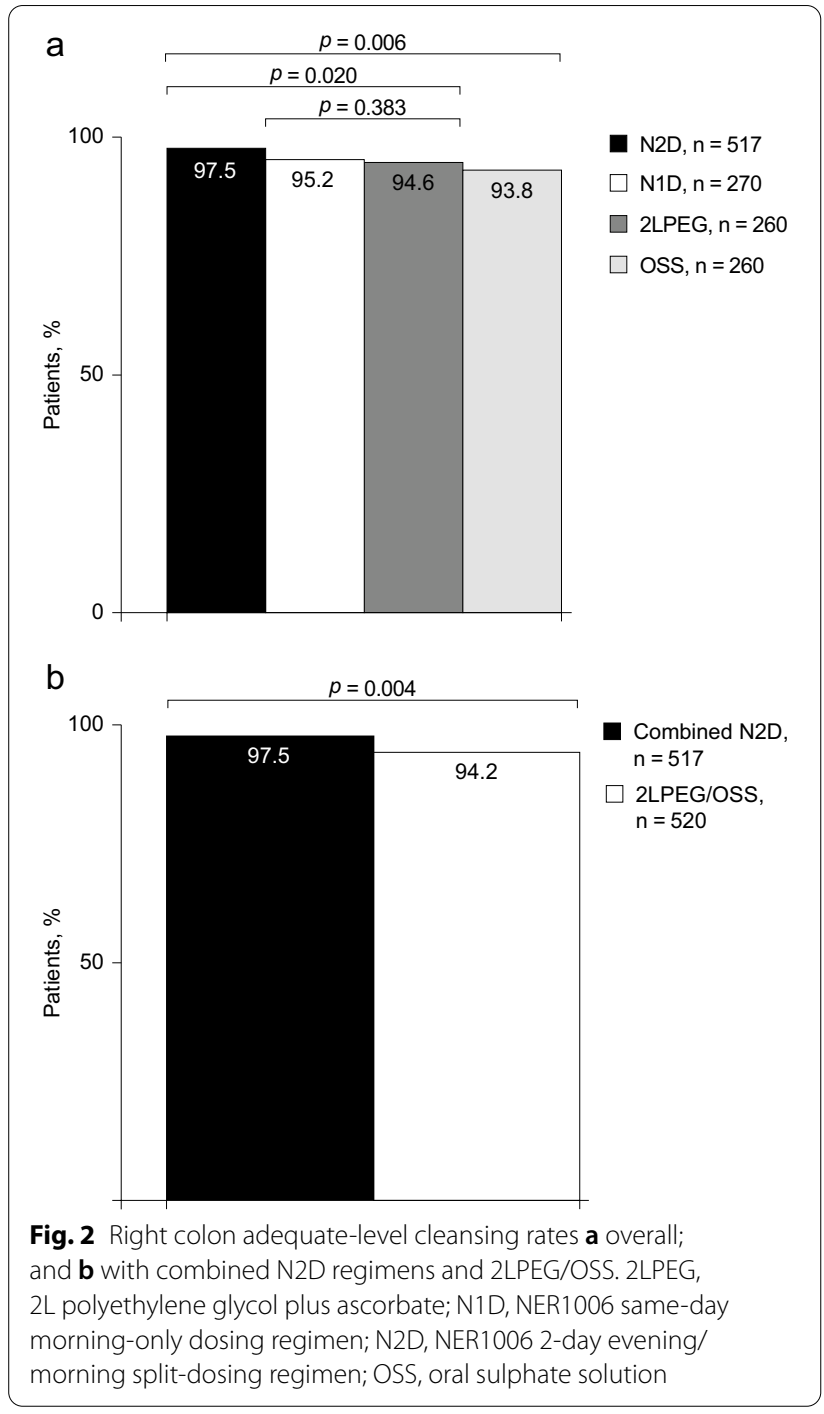

\section{Combined analysis}

Combined data from MORA and NOCT showed significantly higher rates of right colon high-quality cleansing success with N2D versus 2LPEG/OSS (36.0\% [186/517] vs $23.7 \%$ [123/520]; $p<0.001$ ) (Fig. 3b).

\section{Right colon-cleansing success in overweight males} Adequate-level cleansing success in N2D and 2LPEG/OSS

Treatment with NER1006 enabled overweight male colonoscopy patients to attain an adequate-level cleansing success rate in the right colon that was comparable with that of the rest of the patient group (96.5\% [192/199] versus 98.1\% [311/317]; $p=0.253$; Fig. 4a). With 2LPEG/ OSS, the adequate-level cleansing success rate in the right colon was comparable between overweight male patients and all other patients, with no statistically significant difference observed between the groups $(96.0 \%$ [216/225] versus 93.2\% [273/293]; $p=0.166$; Fig. 4a).

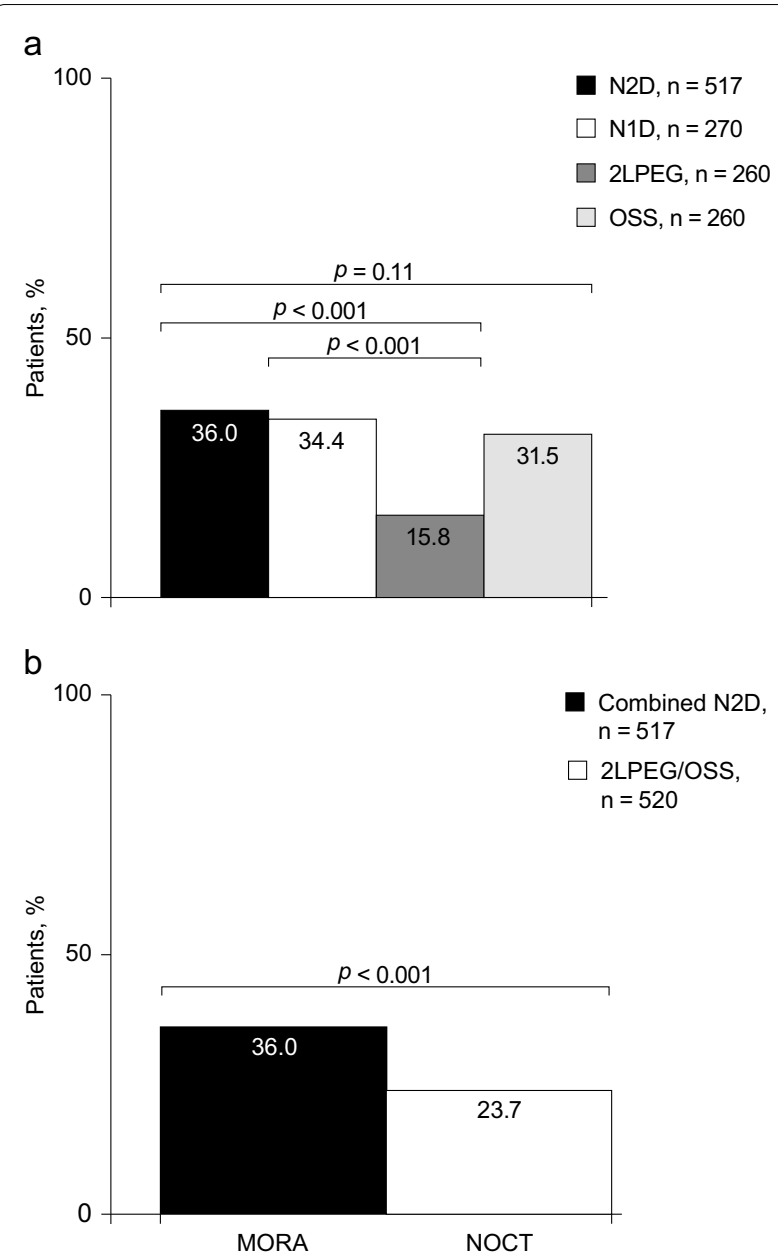

Fig. 3 Right colon high-quality cleansing rates $\mathbf{a}$ overall; and $\mathbf{b}$ with combined N2D regimens and 2LPEG/OSS. 2LPEG: 2L polyethylene glycol plus ascorbate; N1D, NER1006 same-day morning-only dosing regimen; N2D, NER1006 2-day evening/morning split-dosing regimen; OSS, oral sulphate solution

\section{Adequate and high-quality cleansing success in overweight males}

In the combined N2D group, a numerically higher proportion of overweight male patients attained adequate-level cleansing success in the right colon versus the 2LPEG/OSS group (96.5\% [192/199] versus $96.0 \%$ [216/225]; $p=0.398$; Fig. 4b).

The proportion of overweight male patients with high-quality cleansing success in the right colon was significantly higher in the N2D group compared with the 2LPEG/OSS group (32.7\% [65/199] versus $24.0 \%$ [54/225]; $p=0.024$; Fig. 4b). 


\section{a}

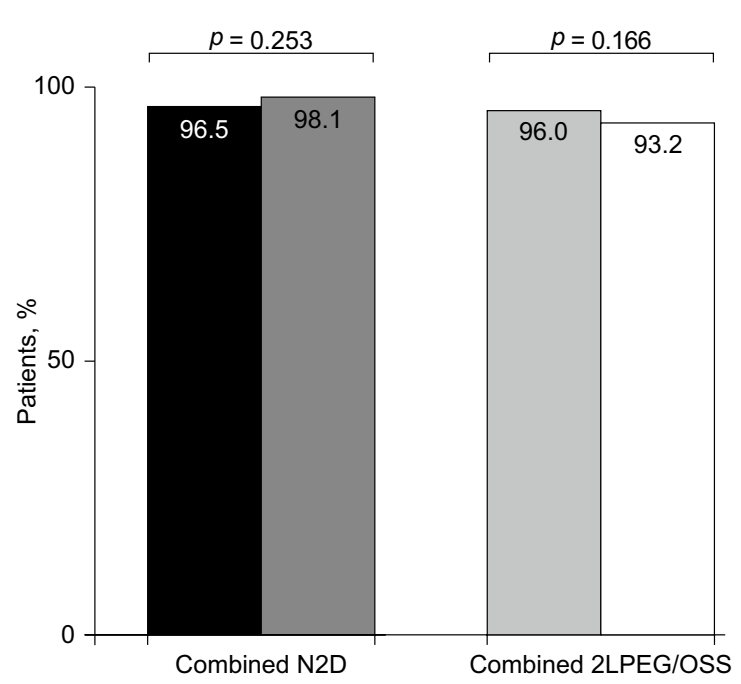

Combined N2D

- Overweight males, $\mathrm{n}=199$

$\square$ All other patients, $\mathrm{n}=317$

Combined 2LPEG/OSS

$\square$ Overweight males, $\mathrm{n}=225$

$\square$ All other patients, $\mathrm{n}=293$

\section{b}

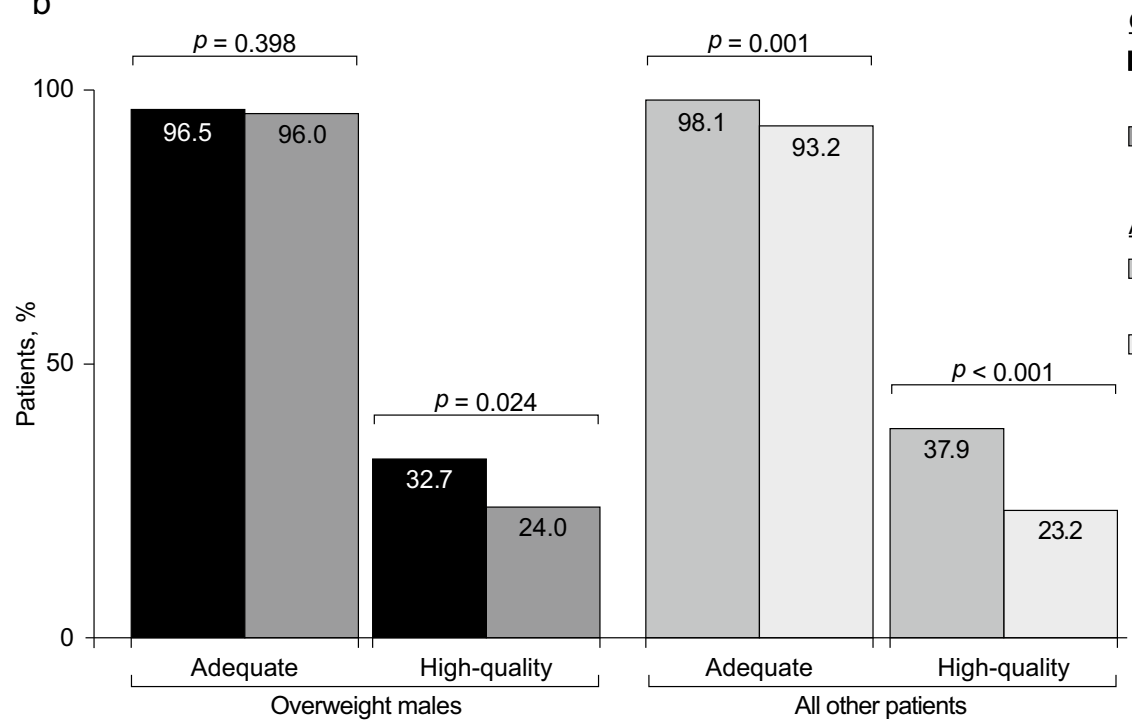

Fig. 4 Right colon cleansing in overweight males by a treatment regimen (adequate cleansing); b patient category. 2LPEG, 2L polyethylene glycol plus ascorbate; N2D, NER1006 2-day evening/morning split-dosing regimen; OSS, oral sulphate solution

\section{Adequate and high-quality cleansing success in all other patients}

In all other patients, the rate of right colon adequate cleansing was superior with N2D versus 2LPEG/OSS (98.1\% [311/317] versus 93.2\% [273/293]; $p=0.001$; Fig. 4b). A significantly higher proportion of patients attained high-quality cleansing in the right colon in the N2D group versus the 2LPEG/OSS group (37.9\% [120/317] versus $23.2 \%$ [68/293]; $p<0.001$; Fig. 4 b).

\section{Multivariable logistic regression on right colon cleansing Adequate right colon cleansing}

In the multivariable logistical regression analysis for factors influencing an outcome of adequate right colon cleansing, there was a significant positive association between adequate cleansing and assignment of NER1006 as the bowel preparation (odds ratio 1.87; 95\% confidence interval $[\mathrm{CI}] 1.06-3.33 ; p=0.031$ ). There was a negative association between the time lapse from preparation to 
colonoscopy and adequate cleansing (OR 0.88 ; 95\% CI $0.79-1.00 ; p=0.034)$.

\section{High-quality right colon cleansing}

In the regression analysis with high-quality right colon cleansing as the outcome, a positive association with NER1006 use was again observed (OR 1.98; 95\% CI 1.53$2.58 ; p<0.001)$. Longer time lapses between preparation and colonoscopy were associated with lower high-quality cleansing rates (OR 0.91; 95\% CI 0.85-0.97; $p=0.006$ ).

\section{Discussion}

This post hoc analysis assessed whether the low-volume PEG-based bowel preparation 1L NER1006 could improve right colon adequate-level and high-quality cleansing success compared with two medium-volume alternatives among patients with complete segmental cleansing data from two randomised controlled trials.

Adequate-level cleansing success is a vital quality metric in colonoscopy [18], and poor bowel preparation can result in missed diagnoses and thereby delay initiation of treatment [19]. Inadequately cleansed patients should, per guideline recommendations, undergo early repeat colonoscopy. Reducing the frequency of early repeat colonoscopies may improve cost effectiveness and also improve patient willingness to undergo the procedure in the future [20-24]. In addition, this inefficiency can lead to delays in attending to other patients on the waiting list.

The right colon is particularly difficult to cleanse to an optimum level for colonoscopy as, following stool clearance from the colon, mucus and chyme that are secreted from the small intestine tend to stick to the caecum and right colon [10]. This increases the risk of missed lesions in the right colon, particularly flat, non-pedunculated lesions and sessile serrated adenomas, which may have a higher malignant potential [7-10, 25]. In our analysis, pooled data from the evening/morning split-dose NER1006 regimens demonstrated a statistically significant higher rate of right colon adequate-level cleansing versus 2LPEG and OSS individually. Compared with 2LPEG, the low volume of NER1006 is achieved by increasing the ascorbate components of the bowel preparation and including them in the second administered dose [26]. This increases the osmotic activity of the preparation relative to $2 \mathrm{LPEG}$ and also enables delivery in a total preparation volume of $1 \mathrm{~L}$ [14]. This enhanced osmotic activity may contribute to improved cleansing of the right colon, as seen in the original studies and detailed in these post hoc analyses [14-16, 27, 29-31].

High-quality cleansing, as assessed by the HCS, is associated with numerically improved adenoma detection in the right colon and significantly improved adenoma detection in the overall colon [27]. In its Phase
III clinical development programme, NER1006 demonstrated numerically improved high-quality cleansing success rates in the right colon versus all of its comparators and a statistically significant improvement over 2LPEG $[14,15]$. In a prospective observational study, a higher proportion of hospitalised patients attained high-quality cleansing in the right colon with NER1006, which was statistically significant, compared with 4LPEG [28]. In the current post hoc analysis, the superior right colon highquality cleansing success rates obtained with NER1006 in the mFAS2 population are therefore consistent with, and an important clarification of, these previous results.

The superior high-quality cleansing success rate with N2D, when assessed strictly by central readers, is consistent with the previously reported superior overall highquality cleansing success of N2D versus 2LPEG or OSS as assessed by site endoscopists [29]. Furthermore, the adequate-level and high-quality cleansing rates attained in the right colon in the combined populations of N2D across both the MORA and NOCT trials were superior to those seen in the combined population of patients treated with 2LPEG or OSS (2LPEG/OSS).

Several risk factors contributing to inadequate bowel cleansing have been identified in the literature, and overweight men are regarded as being at high risk [30]. This specific category of patients is also considered to be at increased risk of CRC, with a high prevalence of colorectal adenomas and polyps in this population [31]. In line with previous studies on cleansing efficacy in highrisk patients, in this study, NER1006 effectively delivered comparable levels of right colon adequate cleansing in both overweight males and all other patients [30]. Similar findings were observed in the 2LPEG/OSS group; however, a numerically higher rate was reported in patients treated with NER1006. The superior overall high-quality cleansing efficacy of NER1006 versus 2LPEG/OSS in overweight men and, separately, in obese male patients older than 60 years, has been reported previously [30, 31]. In the current study, NER1006 maintained its highquality cleansing superiority versus 2LPEG/OSS in the right colon of hard-to-cleanse patients.

This study has several strengths. It is based on two randomised Phase III clinical trials conducted across multiple centres in the USA and Europe to evaluate the cleansing efficacy of the first 1L PEG-based product, NER1006, versus two mid-volume bowel preparations. Importantly, the MORA and NOCT trials were designed with near-identical study protocols, with cleansing assessed by both treatment-blinded endoscopists and central readers using a validated colon-cleansing scale, the HCS. These clinical trials were also the first to be optimised for assessing high-quality cleansing of the right colon as a primary endpoint. The mFAS2, the population 
set used in this analysis, closely resembles the patient population undergoing colonoscopy in real-world clinics.

Our study has limitations. The major source of limitation is the post hoc analysis. The noticeably lower high-quality cleansing success rates observed in this analysis compared with the adequate-level cleansing rates attained in the right colon are due to the criteria strictly applied by central readers for defining high-quality cleansing on the HCS; the perceived cleansing quality by site endoscopists tends to be higher [13,29].

In conclusion, in patients who underwent colonoscopy with full segmental scorings using the HCS by treatmentblinded central readers, N2D demonstrated improved adequate and high-quality cleansing of the right colon compared with 2LPEG and OSS. NER1006 successfully delivered comparable high levels of right colon cleansing in overweight males and all other patients. These cleansing benefits of NER1006 are promising, and will hopefully help healthcare practitioners to further enhance the diagnostic and therapeutic efficacy of colonoscopy in the right colon.

\begin{abstract}
Abbreviations
2LPEG: 2L PEG plus ascorbate; BMI: Body mass index; Cl: Confidence interval; CRC: Colorectal cancer; ESGE: European Society of Gastrointestinal Endoscopy; HCS: Harefield Cleansing Scale; mFAS2: Modified full analysis set 2; OR: Odds ratio; N1D: NER1006 same-day morning-only dosing regimen; N2D: NER1006 2-day evening/morning split-dosing regimen; OSS: Oral sulphate solution; PEG: Polyethylene glycol.
\end{abstract}

\section{Supplementary Information}

The online version contains supplementary material available at https://doi. org/10.1186/s12876-022-02106-2.

Additional file 1. Product formulations of NER1006, OSS and 2LPEG.

\section{Acknowledgements}

The authors would like to thank the investigators and patients for their contributions. Submission, medical writing and editorial assistance was provided by Rory Elsome of TVF Communications, funded by Norgine Ltd. The submission was authorised by all the listed authors.

\section{Authors' contributions}

JM was an investigator in the MORA trial and contributed to data analysis, draft development and clinical review of the manuscript. JH performed the post hoc study design and statistical data analysis, and contributed to the development of manuscript drafts. SJC performed statistical data analysis and medical writing of all drafts. MAA-G was an investigator in the MORA trial, contributed to data analysis, reviewed and edited all drafts, and provided senior clinical guidance to the team. All authors read and approved the final manuscript.

\section{Funding}

The authors received no financial support for the research, authorship and/or publication of this article. JH and SJC were at the time of writing employees of Norgine Ltd.

\section{Availability of data and materials}

All data generated or analysed during this study are available from the corresponding author on reasonable request.

\section{Declarations}

\section{Ethics approval and consent to participate}

The MORA study received ethical review board approval in all participating countries (Commissie Medische Ethiek UZ Leuven, 20 October 2014; Comité de Protection des Personnes Ile-de-France X, 4 November 2014; EthikKommission der Medizinischen Fakultät der Universität Würzburg, 15 October 2014; Komisja Bioetyczna przy Dolnośląskiej Izbie Lekarskiej we Wrocławiu, 12 October 2014; Hospital Clínico San Carlos Comité Ético de Investigación Clínica, 6 November 2014; NRES Committee West Midlands - Coventry and Warwickshire, 15 September 2014). The study was approved by all Italian ehical review boards on 20 November 2014. The NOCT study received United States ethical review board approval on 21 August 2014. Both studies were conducted in accordance with the Declaration of Helsinki. Patients provided written informed consent.

\section{Consent for publication}

Not applicable.

\section{Competing interests}

The authors declared the following potential conflicts of interest with respect to the research, authorship and/or publication of this article: JM has received honoraria from Norgine Ltd for speaking and investigator advisory board attendance. JH and SJC are employees of Norgine Ltd. MAA-G has received honoraria from Norgine Ltd for advisory board attendance and from CasenRecordati for speaking and teaching.

\section{Author details}

${ }^{1}$ Borders General Hospital, NHS Borders, Melrose, Berwickshire, UK. ${ }^{2}$ Norgine Ltd, Medical Affairs, Widewater Place Moorhall Road, Harefield, Uxbridge UB9 6NS, UK. ${ }^{3}$ Hospital del Mar, Digestive Diseases, Barcelona, Spain.

Received: 28 May 2021 Accepted: 5 January 2022

Published online: 25 January 2022

\section{References}

1. Brenner H, Stock C, Hoffmeister M. Effect of screening sigmoidoscopy and screening colonoscopy on colorectal cancer incidence and mortality: systematic review and meta-analysis of randomised controlled trials and observational studies. BMJ. 2014;348:92467.

2. Sharma P, Burke CA, Johnson DA, Cash BD. The importance of colonoscopy bowel preparation for the detection of colorectal lesions and colorectal cancer prevention. Endosc Int Open. 2020;8:E673-83.

3. Kaminski MF, Thomas-Gibson S, Bugajski M, et al. Performance measures for lower gastrointestinal endoscopy: a European Society of Gastrointestinal Endoscopy (ESGE) Quality Improvement Initiative. Endoscopy. 2017:49:378-97.

4. Gimeno-García AZ, Baute JL, Hernandez G, et al. Risk factors for inadequate bowel preparation: a validated predictive score. Endoscopy. 2017:49:536-43.

5. Pohl J, Halphen M, Kloess HR, Fischbach W. Impact of the quality of bowel cleansing on the efficacy of colonic cancer screening: a prospective, randomized, blinded study. PLoS ONE. 2015;10:e0126067.

6. Fischbach W, Elsome R, Amlani B. Characteristics of right-sided colonic neoplasia and colonoscopy barriers limiting their early detection and prognosis: a review of the literature. Expert Rev Gastroenterol Hepatol. 2018;12:585-96.

7. Laiyemo AO, Doubeni C, Sanderson AK II, et al. Likelihood of missed and recurrent adenomas in the proximal versus the distal colon. Gastrointest Endosc. 2011;74:253-61.

8. Rondagh EJ, Bouwens MW, Riedl RG, et al. Endoscopic appearance of proximal colorectal neoplasms and potential implications for colonoscopy in cancer prevention. Gastrointest Endosc. 2012;75:1218-25.

9. Fernandes C, Pinho R, Ribeiro I, Silva J, Ponte A, Carvalho J. Risk factors for polyp retrieval failure in colonoscopy. United Eur Gastroenterol J. 2015;3:387-92.

10. Lasisi F, Rex DK. Improving protection against proximal colon cancer by colonoscopy. Expert Rev Gastroenterol Hepatol. 2011;5:745-54. 
11. Johnson DA, Barkun AN, Cohen LB, et al. Optimizing adequacy of bowel cleansing for colonoscopy: recommendations from the US Multi-Society Task Force on Colorectal Cancer. Am J Gastroenterol. 2014;109:1528-45.

12. Hassan C, East J, Radaelli F, et al. Bowel preparation for colonoscopy: European Society of Gastrointestinal Endoscopy (ESGE) Guideline-Update 2019. Endoscopy. 2019;51:775-94.

13. Ell C, Fischbach W, Bronisch HJ, et al. Randomized trial of low-volume PEG solution versus standard PEG + electrolytes for bowel cleansing before colonoscopy. Am J Gastroenterol. 2008;103:883-93.

14. Bisschops R, Manning J, Clayton LB, Ng Kwet Shing R, Álvarez-González M, MORA Study Group. Colon cleansing efficacy and safety with $1 \mathrm{~L}$ NER1006 versus $2 \mathrm{~L}$ polyethylene glycol + ascorbate: a randomized phase 3 trial. Endoscopy. 2019;51:60-72.

15. DeMicco MP, Clayton LB, Pilot J, Epstein MS, NOCT Study Group. Novel 1 $L$ polyethylene glycol-based bowel preparation NER1006 for overall and right-sided colon cleansing: a randomized controlled phase 3 trial versus trisulfate. Gastrointest Endosc. 2018;87:677-87.e3.

16. Maida M, Sinagra E, Morreale GC, et al. Effectiveness of very low-volume preparation for colonoscopy: a prospective, multicenter observational study. World J Gastroenterol. 2020;26:1950-61.

17. Borg BB, Gupta NK, Zuckerman GR, Banerjee B, Gyawali CP. Impact of obesity on bowel preparation for colonoscopy. Clin Gastroenterol Hepatol. 2009;7:670-5

18. Jang JY, Chun HJ. Bowel preparations as quality indicators for colonoscopy. World J Gastroenterol. 2014;20:2746-50.

19. Janahiraman $S$, Tay CY, Lee JM, et al. Effect of an intensive patient educational programme on the quality of bowel preparation for colonoscopy: a single-blind randomised controlled trial. BMJ Open Gastroenterol. 2020;7:e000376

20. Gluecker TM, Johnson CD, Harmsen WS, et al. Colorectal cancer screening with CT colonography, colonoscopy, and double-contrast barium enema examination: prospective assessment of patient perceptions and preferences. Radiology. 2003;227:378-84.

21. Amlani B, Radaelli F, Bhandari P. A survey on colonoscopy shows poor understanding of its protective value and widespread misconceptions across Europe. PLOS ONE. 2020;15:e0233490.

22. Froehlich F, Wietlisbach V, Gonvers JJ, Burnand B, Vader JP. Impact of colonic cleansing on quality and diagnostic yield of colonoscopy: the European Panel of Appropriateness of Gastrointestinal Endoscopy European multicenter study. Gastrointest Endosc. 2005;61:378-84.

23. Rex DK, Imperiale TF, Latinovich DR, Bratcher LL. Impact of bowel preparation on efficiency and cost of colonoscopy. Am J Gastroenterol. 2002;97:1696-700.

24. Murphy D, Jenks M, McCool R, Wood H, Young V, Amlani B. A systematic review and cost analysis of repeat colonoscopies due to inadequate bowel cleansing in five European countries. Expert Rev Pharmacoecon Outcomes Res. 2019:19:701-9.

25. Clayton LB, Tayo B, Halphen M, Kornberger R. Novel $1 \mathrm{~L}$ polyethylene glycol-based bowel preparation (NER1006): proof of concept assessment versus standard $2 \mathrm{~L}$ polyethylene glycol with ascorbate-a randomized, parallel group, phase 2, colonoscopist-blinded trial. BMC Gastroenterol. 2019;19:79.

26. Murakami T, Sakamoto N, Nagahara A. Clinicopathological features, diagnosis, and treatment of sessile serrated adenoma/polyp with dysplasia/ carcinoma. J Gastroenterol Hepatol. 2019;34:1685-95.

27. Hassan C, Manning J, Álvarez González MA, Sharma P, Epstein M, Bisschops R. Improved detection of colorectal adenomas by high-quality colon cleansing. Endosc Int Open. 2020;8:E928-37.

28. Frazzoni L, Spada C, Radaelli F, et al. 1L-vs. 4L-Polyethylene glycol for bowel preparation before colonoscopy among inpatients: a propensity score-matching analysis. Dig Liver Dis. 2020;52:1486-93.

29. Repici A, Coron E, Sharma P, et al. Improved high-quality colon cleansing with $1 \mathrm{~L}$ NER1006 versus $2 \mathrm{~L}$ polyethylene glycol + ascorbate or oral sulfate solution. Dig Liver Dis. 2019;51:1671-7.

30. Baile-Maxia S, Amlani B, Martínez RJ. Bowel-cleansing efficacy of the $1 \mathrm{~L}$ polyethylene glycol-based bowel preparation NER1006 (PLENVU) in patient subgroups in two phase III trials. Ther Adv Gastroenterol. 2021;14:17562848211020286.

31. Epstein M, Halonen J, Sharma P. Bowel preparation with the $1 \mathrm{~L}$ polyethylene glycol and ascorbate NER1006 doubles the chance to detect three or more adenomas in overweight or obese males. Endosc Int Open. 2021;9:E1324-34.

\section{Publisher's Note}

Springer Nature remains neutral with regard to jurisdictional claims in published maps and institutional affiliations.
Ready to submit your research? Choose BMC and benefit from:

- fast, convenient online submission

- thorough peer review by experienced researchers in your field

- rapid publication on acceptance

- support for research data, including large and complex data types

- gold Open Access which fosters wider collaboration and increased citations

- maximum visibility for your research: over $100 \mathrm{M}$ website views per year

At BMC, research is always in progress.

Learn more biomedcentral.com/submissions 